\title{
A abertura do capital estrangeiro ao setor saúde: os debates que envolvem o tema
}

The opening of foreign capital to the health sector: the debates surrounding the topic

La apertura del capital extranjero en el sector de la salud: los debates en torno al tema

Évelin Mauricio Brito ${ }^{1}$

Alethele de Oliveira Santos ${ }^{2}$

RESUMO: O artigo 142 da Lei n. 13.097/2015 indicou a abertura do capital estrangeiro ao setor saúde e alterou a Lei n. 8.080/90. A alteração da lei orgânica da saúde provocou debates acerca da constitucionalidade, possíveis benefícios e malefícios da permissão. $O$ presente artigo apresenta os consensos e dissensos dos argumentos existentes no debate, o processo legislativo pelo qual se deu a positivação da lei, e, identifica a ocasião em que se deu, de fato, a entrada do capital internacional ao setor saúde no país. Os resultados foram obtidos a partir de revisão bibliográfica.

Palavras-chaves: Processo legislativo. Capital estrangeiro. Setor saúde. Saúde suplementar.

ABSTRACT: The article 142 of Law n. 13.097/2015 indicated the opening for foreign capital to health sector and changed the Law n. 8.080/90. Changing the organizational structure of the health law sparked discussions about its constitutionality, possible benefits and harms of permission. This article presents the consensus and dissents on existing arguments in the debate, the legislative process by which gave the law, and identifies when it happened, the entry of international capital to the health sector in the country. The results were obtained from literature review

Keywords: Legislative process. Foreign capital. Health sector. Health insurance.

RESUMEN: El artículo 142 de la Ley n. 13097/2015 indica la apertura para el capital extranjero en el sector de la salud y cambia la ley n. 8.080/90. Cambió la estructura organizativa de la ley de salud y provocó discusiones sobre la constitucionalidad, los posibles riesgos y beneficios de permiso. El presente artículo presenta los consensos y disensos de los argumentos existentes en el debate, el proceso legislativo que hizo la positivación de la ley, e identifica el tiempo que ha pasado, de hecho, la entrada del capital internacional para el sector salud en el país. Los resultados se obtuvieron a partir de una revisión de la literatura.

Palabras-llave: Proceso legislativo. Capital extranjero. Sector salud. Seguro de salud.

\footnotetext{
${ }^{1}$ Bacharel em Saúde Coletiva, Sanitarista pela Universidade de Brasília - UNB. Avaliadora do Programa Nacional de Avaliação dos Serviços de Saúde - PNASS - Ministério da Saúde. Brasília,DF. Brasil.E-mail:evelinmbrito@gmail.com 2 Doutoranda pela Faculdade de Saúde Coletiva da UnB, Advogada, Assessora Técnica do Conselho Nacional de Secretários de Saúde - CONASS, Brasília,DF Brasil. E-mail: alethele.ig.com.br.
} 


\section{Introdução}

A saúde, desde a promulgação da Constituição Federal de 1988 (CF/88) é um bem inalienável ao qual todos os cidadãos têm direito. Para além do artigo 6ํ da CF, o artigo 196 expressa que "A saúde é direito de todos e dever do Estado" (1).

A Lei $n^{\circ}$ 8.080, de 1990 (2) orienta que o acesso às ações e serviços de saúde que são prerrogativas do cidadão, devem ser asseguradas segundo os princípios da universalidade e integralidade. Para Paim (3), universal é "aquilo que é comum a todos", enquanto a integralidade carrega sentido "polissêmico" e é definida pela lei orgânica como "um conjunto articulado e contínuo das ações e serviços preventivos e curativos, individuais e coletivos, exigidos para cada caso em todos os níveis de complexidade do sistema" (2).

Para subsidiar tamanha densidade, conta-se com responsabilidades comuns e específicas dos entes federados. Dentre as responsabilidades comuns, está o pano de fundo do escopo desse estudo - que é o financiamento. O financiamento à saúde é tripartite, conta com um emaranhado de leis e é monetariamente limitado, enquanto as necessidades da população são crescentes, ilimitadas e dotadas de especificidades. Essa assimetria denota a inexistência de uma conta convergente onde as receitas se coadunem com as despesas, para fazer girar esse mundo complexo que é a assistência à saúde.

Nesses muitos debates sobre o tema financiamento da saúde, a sanção da Lei no 13.097 de 19 de janeiro de 2015 (4) provocou um aumento nas discussões na seara sanitária. Isso porque a lei sancionada pela Presidente Dilma Rousseff, além de ser uma normatização que carrega em si uma larga mistura de assuntos, compreende no artigo 142, abertura ao investimento financeiro externo na saúde no Brasil.

Há quem compreenda que a entrada do capital estrangeiro na saúde no Brasil não é um ato novo. Há muito tempo os países emergentes lidam com os movimentos de capitais dentro de setores estratégicos. Nesse sentido Guimarães (5), indica que "acreditando na igualdade de capitais, o Brasil promoveu radical desregulamentação de seus movimentos, inclusive privilegiando ostensivamente o capital estrangeiro". 
Compete ainda apresentar a lei no 9.656/98, que regulamenta os planos privados de saúde, em especial no artigo $1^{\circ}$, $\S 3^{\circ}$, o que pode significar a primeira permissão legal para a atuação do capital estrangeiro no setor saúde (6):

As pessoas físicas ou jurídicas residentes ou domiciliadas no exterior podem constituir ou participar do capital, ou do aumento do capital, de pessoas jurídicas de direito privado constituídas sob as leis brasileiras para operar planos privados de assistência à saúde.

Ao salientar que o sistema de saúde brasileiro é híbrido, a reflexão que se impõe são as relações, inclusive do financiamento, imbricadas entre o SUS e Saúde Suplementar. Segundo os economistas Mendes e Levi (7) o Brasil é um país onde o financiamento do setor privado $(51,7 \%)$ é maior do que o do setor público $(48,3 \%)$, revelando que o atendimento a um número menor de usuários demanda maiores quantidades de dinheiro, o que demonstra o frágil cenário no qual o SUS está inserido.

Destaca-se também a ligação entre SUS e sistema privado dada a existência da chamada "saúde complementar", prestada por instituições privadas mediante convênios ou contratos de direito público, e, não deixam de ser "assistência do SUS" (8). Sarlet e Figueiredo (8) salientam que a saúde complementar "envolve uma atividade delegada à iniciativa privada (excluída a participação de empresas ou capitais estrangeiros), que atua em lugar da Administração Pública".

O objetivo desse artigo é apresentar, de forma didática, os consensos e contrapontos das discussões existentes, assim como o processo legislativo que positivou tal permissão, sem, contudo, ter a pretensão de indicar os impactos do artigo 142 da lei $n^{\circ}$ 13.097/2015 (4), ou proferir parecer acerca da constitucionalidade do dispositivo. Apresenta também os esforços de identificação acerca da entrada (de fato) dos investimentos financeiros externos no setor saúde.

\section{Metodologia}

Esse artigo foi escrito a partir de revisão bibliográfica e análise do processo legislativo que propôs a entrada de capital estrangeiro no setor saúde. A revisão bibliográfica, segundo Mattos, (9) "possibilita a contextualização sobre o assunto empreendido", "subsidia a problematização e uma primeira validação do quadro teórico a ser utilizado no processo de investigação". 
Para tanto, foram identificados artigos científicos disponibilizados na Biblioteca Virtual em Saúde (BVS), que compreende as bases: LILACS, IBECS, MEDLINE, Biblioteca Cochrane e SciELO ${ }^{3}$ e artigos disponibilizados pela plataforma Google Acadêmico.

Também foram utilizados, a título de complementação, artigos de opinião de autoridades sanitárias e do direito, obtidos a partir de consulta em variadas fontes no endereço eletrônico do Centro Brasileiro de Estudos de Saúde - CEBES, reportagem eletrônica de jornal de larga circulação e outras, devidamente identificadas no decorrer do texto.

Em primeira busca, foi consultada a BVS e utilizado exclusivamente o descritor "capital estrangeiro", em idioma nacional, nos anos 2009 à 2015, para textos integralmente disponíveis. Os resultados demonstraram 6 arquivos, dos quais, após "leitura flutuante" (10), restou Scheffer (11) como único conteúdo compatível ao assunto estudado.

Ao considerar a dificuldade de encontrar artigos sobre 0 assunto, tal fato corroborou para a decisão de ampliar as buscas para a plataforma google acadêmico. Nessa plataforma, ao contrário da BVS, não há especificidade da temática saúde, motivo pelo qual foram utilizados os descritores: (i) "capital estrangeiro"; (ii) "saúde" e (iii) "13.097", como forma de refinamento da busca, pesquisados os anos 2009 à 2015, em idioma nacional. Foram encontrados 13 arquivos, e após leitura flutuante (10), restaram 6: Sacramento (12); Barros, et al (13), Monken, et al (14), Mendes, et al (15); Costa, et al (16), Conselho Municipal de Saúde de São Paulo (CMS.SP) (17). Resta observar que Scheffer (11), foi encontrado em ambas as bases pesquisadas e considerado única vez.

Sobre o capital estrangeiro na setorial saúde, também foram descritos os fundamentos e os trâmites legislativos do Projeto de Lei do Senado (PLS) 259 /2009 (18). Da mesma forma para a Medida Provisória 656/2014 (19) - que culminou na lei no 13.097/2015 - a partir das informações contidas no espaço eletrônico do Senado Federal.

\footnotetext{
${ }^{3}$ LILACS - Literatura Científica e Técnica da América Latina e Caribe de Ciências da Saúde. IBECS - Índice Bibliográfico Espanhol de Ciências da Saúde da Espanha. 
Com a intenção de apresentar os fundamentos utilizados na Ação Direta de Inconstitucionalidade $\mathrm{n}^{-}$5239/2015 (20) interposta pela Confederação Nacional dos Trabalhadores Liberais Universitários Regulamentados em face da lei e o parecer da Procuradoria Geral da União (PGR) (21) foi consultado o espaço eletrônico do Supremo Tribunal Federal (STF) - responsável pela análise e julgamento da ação.

Ultrapassada a fase de captação de material de pesquisa, os artigos científicos foram estratificados de modo a identificar pontos comuns e divergentes entre os autores. Posteriormente esses pontos foram confrontados com os artigos de opinião da bibliografia complementar.

Da mesma forma, buscou-se identificar na justificação e trâmite do processo legislativo, os fundamentos utilizados para sua aprovação comparados aos artigos já analisados.

Indicados os pontos comuns entre artigos científicos, da literatura complementar e da justificação legislativa, buscou-se entender as razões pelas quais o artigo 142 da lei no 13.097/2015 foi levado ao questionamento de constitucionalidade junto à Corte Constitucional Brasileira e se seu fundamento encontra guarida nos artigos analisados.

Por fim, houve a elaboração de tabelas para a visualização dos resultados de uma maneira mais objetiva, bem como análise das mesmas, apresentação e discussão de resultados.

\section{Resultados e discussão}

Ao executar a revisão da literatura, foi possível encontrar resultados, que permitiram a sistematização do tema. A Lei n. 13.097/15 (4) alterou o disposto na Lei $n$. 8.080/90 (2) acerca da vedação ao investimento de capital estrangeiro no setor saúde. Com essa modificação, passou-se a permitir que recursos externos pudessem ser alocados na área de assistência á saúde, inclusive em hospitais filantrópicos.

Dos artigos selecionados para a pesquisa, cabe apresentar os conceitos trazidos por Scheffer (11), Sacramento (12), Barros et al (13), Monken et al (14), Mendes (15), Costa (16), e CMS.SP (17). Da mesma forma buscou-se identificar a menção dos autores acerca da entrada do capital estrangeiro no setor saúde e a menção de fundamento jurídico para tanto. 
Tabela I - Conceitos, Ano e fundamento jurídico para a entrada do capital estrangeiro no setor saúde brasileiro.

\begin{tabular}{|c|c|c|c|}
\hline Autor & $\begin{array}{c}\text { Conceito de Capital } \\
\text { Estrangeiro }\end{array}$ & $\begin{array}{l}\text { Ano/ Entrada do } \\
\text { Capital Estrangeiro } \\
\text { na saúde do Brasil }\end{array}$ & $\begin{array}{l}\text { Fundamento } \\
\text { Jurídico }\end{array}$ \\
\hline Scheffer, 2015 & $\begin{array}{l}\text { "Empresas multinacionais, no } \\
\text { caso dos investimentos e do } \\
\text { comércio, grandes bancos, no } \\
\text { caso dos financiamentos, e } \\
\text { aos fundos de pensão que } \\
\text { operam capital } \\
\text { especulativo". or (Apud } \\
\text { Guimarães SP, 2000). }\end{array}$ & 1998 & $\begin{array}{l}\text { Leis } 9.656 / 1998 \text { e } \\
13.097 / 2015 \text { (art. } \\
142)\end{array}$ \\
\hline Sacramento, 2015 & Não conceitua & 2015 & Lei 13.097/2015 \\
\hline Barros et al, 2015 & Não conceitua & 2015 & Lei 13.097/2015 \\
\hline Monken et al, 2015 & $\begin{array}{l}\text { Fontes de financiamento } \\
\text { Internacionais/ Capital vindo } \\
\text { do exterior. }\end{array}$ & 2015 & Lei 13.097/2015 \\
\hline Mendes, 2015 & $\begin{array}{l}\text { Inclui no conceito a permissão } \\
\text { de aquisição de santas casas. }\end{array}$ & 2015 & Lei $13.097 / 2015$ \\
\hline Costa, 2015 & Não conceitua & & \\
\hline CMS.SP, 2015 & Não conceitua & 2015 & Lei 13.097/2015 \\
\hline
\end{tabular}

Da tabela I é possível observar informação divergente entre os autores, acerca do ano em que o capital estrangeiro passou a ser admitido no país. Da mesma forma o fundamento jurídico que admitiu, segundo os autores selecionados, a entrada de capital estrangeiro na saúde, variou conforme o ano em que eles consideraram a existência de permissão legal. Todavia, dentre os autores apresentados na tabela, é majoritária a ideia de que o evento decorre da Lei n. 13.097/2015.

A par da divergência acerca da entrada do capital estrangeiro no setor saúde brasileiro, compete apresentar, da literatura complementar, a opinião de Santos (22), que identifica o início da entrada do capital estrangeiro no Brasil, em 1962, em face da Lei n. 4.131/62, art $1^{\circ}$ que conceitua capital estrangeiro como:

Bens, máquinas e equipamentos, entrados no Brasil sem dispêndio inicial de divisas, destinados à produção de bens ou serviços, bem como os recursos financeiros ou monetários introduzidos no país, para aplicação em atividades econômicas desde que, em ambas as hipóteses pertençam a pessoas físicas ou jurídicas residentes, domiciliadas ou com sede no exterior. 
Scheffer considera que o investimento externo no setor saúde já estava em decurso no país, desde a Lei n. 9.656/1998 (6):

[...] a saúde já estava parcialmente aberta a investidores internacionais que tornaram-se acionistas de empresas de planos de saúde e de grupos hospitalares ligados a elas. Recursos de origem estrangeira também haviam sido aportados em laboratórios de exames diagnósticos, neste caso de modo não autorizado, mas consentido pelos órgãos governamentais.

Compete também apresentar artigo de opinião convergente, em alguma medida, à de Santos (22) e de Scheffer (11). Trata-se daquela que foi emitida pelo ministro da saúde, à época da promulgação da Lei n. 13.097/2015(4), Arthur Chioro (23) para quem as "operadoras de capital internacional foram autorizadas a comprar planos de saúde no Brasil; a Amil foi comprada pela empresa United Health em 2012, e a Itermédica vendida para o grupo de investimento americano Bain Capital." De seu discurso extrai-se também que "depois destas compras, as empresas passaram a adquirir hospitais próprios"; "o jogo já estava aberto"; "a abertura do capital já havia acontecido e de forma assimétrica"; "ao longo desse período ocorreu um processo 'lento e gradual' de abertura para o capital estrangeiro" (23)

A afirmativa de Chioro (23) é ratificada por Santos (24) quando refere-se ao tema fusões e aquisições em saúde:

A compra, por 10 bilhões de reais, da AML, maior operadora de planos de saúde brasileira, foi aprovada pela Agencia Nacional de Saúde Suplementar - e realizada pelo grupo norte-americano United Health Group, datada em 8 de outubro de 2012, abrangendo 22 hospitais da rede própria da Amil.

Ainda de acordo com Chioro (23), aqueles que se colocam contra o art. 142 da nova lei, sofrem de "antagonismo político inadequado" e "falta de capacidade de análise a fundo da matéria". Defende o ministro que não haverá maleficio algum ao SUS. Nesse mesmo caminho, Monken et al (14) afirmam que a abertura ao capital estrangeiro proporciona benefícios e novos conceitos ao setor saúde, necessitando, todavia, sejam feitas adequações aos modelos de gestão vigentes.

Entretanto, em caminho oposto, Costa et al (16) consideram que a lei n. 13.097 (4) representa um retrocesso, pois fere diretamente a soberania nacional na condução das 
políticas de saúde no país. Compartilham deste pensamento CMS.SP (17) ao exprimir opinião de inconstitucionalidade, e Sacramento (12) que identifica a lei como "ameaçadora" ao SUS.

Destaca-se a expressão de Mendes (15) para quem é problemática a liberação da expansão da entrada de capitais estrangeiros na assistência à saúde. Reitera que com tal medida, há um "progressivo alargamento do setor privado no subsistema SUS", ao mesmo tempo em que contribui para a "crescente precarização dos seus serviços" ao gerar a "flexibilização dos vínculos trabalhistas." (15)

Ainda nessa tese, destaca-se a entrevista dada pelo Presidente, à época, da Associação Brasileira de Saúde Coletiva (Abrasco), Luís Eugênio Souza (25) quando afirma possuir a esperança de que a lei seja considerada inconstitucional, pois é contrária a estruturação de um sistema público de saúde.

Há uma ação muito bem articulada dos atores interessados na mercantilização da saúde. Esses interesses são bem representados no parlamento, inclusive por meio do financiamento de campanhas de vários deputados, senadores, e também de candidatos ao Executivo. Objetivamente, a situação é muito difícil do ponto de vista da manutenção de um Sistema Único de Saúde.

A tabela II presta-se a ilustrar os argumentos anteriormente apresentados e pode validar aqueles que querem crer que a lei n.13.097/15 (4), veio regulamentar ação já existente nas práticas econômicas do Estado brasileiro para o setor saúde, assim como aos que consideram, como Mendes (15) que essa lei é inovadora e não encontrava respaldo em nenhum outro fundamento jurídico.

Tabela 2 - Cronologia dos dispositivos que referiram capital estrangeiro no setor saúde.

\begin{tabular}{cll}
\hline Ano & Dispositivo & $\begin{array}{l}\text { Assunto } \\
\text { Veda a participação de empresas ou } \\
\text { capital estrangeiro na saúde, salvo } \\
\text { casos previstos em lei (Artigos 199 } \S \\
3^{\circ} \text { ). }\end{array}$ \\
& Lei Orgânica da Saúde. Promoção, \\
1988 & Lei 8080/90 & $\begin{array}{l}\text { Leteção e recuperação da saúde a } \\
\text { prganização e o funcionamento dos } \\
\text { serviços correspondentes }\end{array}$ \\
1990 & Lei 9.656/98 & $\begin{array}{l}\text { Regulamenta os Planos Privados de } \\
\text { saúde e Lei n. 13.097/2015 }\end{array}$
\end{tabular}




\begin{tabular}{lll}
2009 & PLS 259/15 & $\begin{array}{l}\text { Altera a Lei o } 8.080, \text { de } 19 \text { de } \\
\text { setembro de 1990, para permitir a } \\
\text { participação de empresa e de capital } \\
\text { estrangeiro na assistência à saúde. }\end{array}$ \\
2015 & $13.097 / 15$ & $\begin{array}{l}\text { Art. 142 - Abre o setor saúde ao } \\
\text { capital estrangeiro. }\end{array}$ \\
\hline
\end{tabular}

Fonte: elaboração da $1^{\text {a }}$ autora

Nessa discussão sobre a cronologia das leis, cabe trazer aos debates o Projeto de Lei do Senado (PLS 259/2009) (18), de autoria do então Senador Flexa Ribeiro, que propôs a alteração da Lei no 8.080 /1990(2) de modo a permitir a participação de empresas internacionais e de capital estrangeiro na assistência à saúde.

O PLS 259/2009 foi encaminhado à Comissão de Constituição, Justiça e Cidadania (CCJC) em 10 de dezembro de 2014 para análise, e, alterações de conteúdo foram propostas. Nesse sentido a CCJC propôs limitações ao PLS original de modo a contemplar: (i) que a participação de capital estrangeiro ocorresse por intermédio de doação de organismo internacional vinculado à Organização das Nações Unidas (ONU), além de entidade de cooperação técnica e de financiamento e empréstimo; (ii) que fosse restrita a um elenco de ações e serviços ou à autorização do órgão nacional do SUS; (iii) que a exploração se desse por pessoa jurídica organizada sob a forma de sociedade anônima com, no mínimo, $51 \%$ do capital votante pertencente a brasileiros natos ou naturalizados há mais de dez anos; (iv) fosse facultada a participação do capital estrangeiro em hospital geral filantrópico e em serviço de saúde sem fim lucrativo (18).

Com fundamento no regimento Interno do Senado Federal, a CCJC entendeu que foram atendidos os preceitos de técnica legislativa, jurisdicidade e constitucionalidade, que não havia vício de iniciativa do projeto (18), o que foi ratificado pelo fundamento nos artigos 24, incisos I e XII, art. 48, inciso XIII, e art. 61, §1ํ da CF. (18) (1). Contudo, na análise da Comissão de Assuntos Econômicos (CAE), ocorrida em 9 de dezembro de 2014, as limitações anteriormente apresentadas foram excluídas por meio de substitutivo. O processo do Projeto de Lei 259, de 2009, encontra-se em tramitação e até a elaboração desse artigo encontrava-se encaminhado à Comissão de Relações Exteriores e Defesa Nacional, para prosseguimento (18).

O fundamento legal para a entrada de capital estrangeiro utilizados no PLS 259/2009 é o artigo 197 da CF. Segundo o senador Flexa (18), o dispositivo consiste em 
uma autorização indireta para que o capital estrangeiro seja investido em setores da saúde. De acordo com o projeto, há incongruência ao liberar a saúde ao setor suplementar e não liberá-la ao capital internacional. Indica por benefício a promoção da concorrência, preços da assistência à saúde menos onerosos à população, ao SUS e aos planos privados, sem ressaltar em nenhum momento, malefícios, porventura existentes. O PLS (18) e nem sua justificação indicam quando, se e de que forma ocorreu a entrada de capital estrangeiro no setor saúde.

Ainda que não seja objetivo do presente artigo, não poderia deixar de mencionar, que Barros et al (13) destaca que não houve discussão com a sociedade sobre o tema, em período anterior a aprovação da lei 13.097/15 (4). No mesmo raciocínio, Scheffer (11) afirma que não houve extensão do assunto aos membros da sociedade civil e os fóruns de participação social.

Ao comparar o PLS com os autores Scheffer (11), Sacramento (12), Barros et (13), Monken (14), Mendes (15), Costa (16), CMS.SP (17) e Santos (22) nota-se a diferença de entendimento. Para Santos (22), o fundamento legal para a entrada de capital estrangeiro deu-se com a lei n. 4.131/62 (26) reguladora do capital estrangeiro ou ainda, a lei n. 9.656/98 (6) reguladora da saúde suplementar.

Portanto, o fundamento legal apresentado no PLS, que é o artigo 197 da CF, não coincide com os fundamentos dos artigos selecionados. Comparado o elenco de benefícios, Santos (22) afirma que "o capital estrangeiro proporciona o crescimento da economia dos países emergentes, se bem regulado. "Contudo, ressalta os riscos às empresas nacionais na medida em que "porventura ocorra concessão de benefícios fiscais às multinacionais e aos trabalhadores", "na hipótese de diminuição de direitos do trabalhador para que o mercado brasileiro se torne mais vantajoso para investimentos externos". Daí a necessidade de regulação por parte do Estado, de modo a evitar ou minimamente atenuar a dominação de mercado.

No final do ano de 2014, o assunto capital estrangeiro na saúde, foi inserido na Medida Provisória 656/2014 (19), que tratou de assuntos variados, como atualização de tabela do imposto de renda, aerogeradores, negociação das dívidas de time de futebol e nesse mix de proposições, encontrava-se a abertura do capital estrangeiro ao setor saúde. 
Em relação lei no 13.097/2015 (4), é preciso comentar que essa não foi elaborada nos trâmites originais. Como decorre de medida provisória que transcende matéria única (compreendia 29 assuntos), há que se entender pela inobservância da Lei Complementar no 95/ 1988 (27) quando expressa que "a lei tratará de um único objeto" e ainda que "a lei não conterá matéria estranha a seu objeto ou a este não vinculada por afinidade, pertinência ou conexão"

O Supremo Tribunal federal - STF (28) no dia 15 de outubro de 2015, ratificou ser inconstitucional as manobras parlamentares conhecidas como "contrabando legislativo" - que se trata de inclusão de assuntos estranhos à matéria das medidas provisórias em trâmite no Congresso Nacional.

Com fundamento na normativa complementar e outros fatores adiante analisados, foi impetrada uma Ação Direta de Inconstitucionalidade (ADI no 5239/2015) junto ao STF pela Confederação Nacional de Trabalhadores Universitários Regulamentados (CNTU).

A Ação Direta de Inconstitucionalidade ${ }^{4}$ segundo o glossário jurídico do STF, (29) consiste em um instrumento pertencente ao que juristas denominam de "controle concentrado de constitucionalidade das leis". Tem por finalidade declarar que uma lei ou parte dela é inconstitucional, ou seja, dispõe de elementos que contrariam a CF.

Quadro I - Fundamentos apresentados pelas partes, segundo parecer da PGR sobre a ADI 5239/15

\footnotetext{
4 Com base na lei 9.868, de 10 de novembro de 1999, (31) a ADI pode ser interposta pelo: i) Presidente da República, ii) Senado Federal, iii) Câmara dos Deputado, iv) Assembleia Legislativa ou Câmara Legis lativa do Dis trito Federal, v) Governador de Estado ou o Governador do Distrito Federal, vi) Procurador-Geral da República, vii) Conselho Federal da Ordem dos Advogados do Brasil, viii) partido político com represen tação no Congresso Nacional, viiii) confederação sindical ou entidade de classe de âmbito nacional.
} 


\begin{tabular}{|c|c|c|c|c|c|}
\hline Fundamento & CNTU & PR & $\mathrm{CN}$ & AGU & PGR \\
\hline $\begin{array}{l}\text { A lei } n^{\circ} \text {. } \\
\text { 13.097/2015 (art. } \\
142) \text { é } \\
\text { inconstitucional } \\
\text { face ao artigo } \\
199, \S 3 \text { da CF. } \\
\text { (1) }\end{array}$ & $\begin{array}{l}\text { Sim. Cabe ao } \\
\text { Estado o } \\
\text { dever de } \\
\text { prover e } \\
\text { assegurar } \\
\text { acesso à } \\
\text { saúde sem } \\
\text { recorrer ao } \\
\text { capital } \\
\text { estrangeiro. }\end{array}$ & $\begin{array}{l}\text { Não. A lei } \\
\text { atende ao } \\
\text { dever } \\
\text { constituciona } \\
\text { I imposto } \\
\text { pelo art. } 196 \\
\text { da CF. }\end{array}$ & $\begin{array}{l}\text { Não. A lei } \\
\text { atende ao } \\
\text { dever } \\
\text { constitucional } \\
\text { imposto pelo } \\
\text { art. } 196 \text { da } \\
\text { CF. }\end{array}$ & $\begin{array}{l}\text { Não. A lei atende } \\
\text { a intenção do } \\
\text { legislador de } \\
\text { recorrer à } \\
\text { iniciativa privada } \\
\text { como agente } \\
\text { complementar na } \\
\text { promoção da } \\
\text { saúde. }\end{array}$ & $\begin{array}{l}\text { Não. A lei } \\
\text { atende a } \\
\text { determinação } \\
\text { do art. } 196 \text { da } \\
\text { CF. e guarda } \\
\text { pertinência } \\
\text { com a } \\
\text { ideologia } \\
\text { constitucional } \\
\text { alicerçada no } \\
\text { direito à } \\
\text { saúde e na } \\
\text { livre } \\
\text { iniciativa. }\end{array}$ \\
\hline $\begin{array}{l}\text { A lei } n^{\circ} \text {. } \\
13.097 / 2015 \text { (art. } \\
142) \text { é } \\
\text { inconstitucional } \\
\text { face ao artigo } \\
200 \text {, inciso I, da } \\
\text { CF. (1) }\end{array}$ & $\begin{array}{l}\text { Sim. A lei } \\
\text { infringe a } \\
\text { competência } \\
\text { do SUS de } \\
\text { controlare } \\
\text { fiscalizar } \\
\text { procedimento } \\
\text { s, produtos, e } \\
\text { substancias } \\
\text { de interesse à } \\
\text { saúde. }\end{array}$ & $\begin{array}{l}\text { Não. A } \\
\text { presença do } \\
\text { capital } \\
\text { estrangeiro } \\
\text { na } \\
\text { assistência } \\
\text { saúde não } \\
\text { afasta as } \\
\text { competência } \\
\text { s do SUS. }\end{array}$ & $\begin{array}{l}\text { Não. A } \\
\text { presença do } \\
\text { capital } \\
\text { estrangeiro na } \\
\text { assistência à } \\
\text { saúde não } \\
\text { afasta as } \\
\text { competências } \\
\text { do SUS. }\end{array}$ & & $\begin{array}{l}\text { Não. A } \\
\text { presença do } \\
\text { capital } \\
\text { estrangeiro } \\
\text { na } \\
\text { assistência à } \\
\text { saúde não } \\
\text { afasta as } \\
\text { competências } \\
\text { do SUS. }\end{array}$ \\
\hline $\begin{array}{l}\text { A CNTU é } \\
\text { legítima para } \\
\text { propor a ADI. }\end{array}$ & $\begin{array}{l}\text { Sim. } \\
\text { Enquanto } \\
\text { Confederação } \\
\text { sindical é } \\
\text { legítima. }\end{array}$ & $\begin{array}{l}\text { Não. } \\
\text { llegitimidade } \\
\text { ativa } \\
\text { decorrente } \\
\text { de falta de } \\
\text { pertinência } \\
\text { temática. }\end{array}$ & $\begin{array}{l}\text { Não. } \\
\text { llegitimidade } \\
\text { Ativa } \\
\text { decorrente de } \\
\text { falta de } \\
\text { pertinência } \\
\text { temática }\end{array}$ & $\begin{array}{l}\text { Não. llegitimidade } \\
\text { Ativa decorrente } \\
\text { de falta de } \\
\text { pertinência } \\
\text { temática }\end{array}$ & $\begin{array}{l}\text { Não. } \\
\text { llegitimidade } \\
\text { Ativa } \\
\text { decorrente de } \\
\text { falta de } \\
\text { pertinência } \\
\text { temática }\end{array}$ \\
\hline
\end{tabular}

Fonte: Elaboração da 1a Autora com base nas informações coletadas da Presidência da República (PR), do Congresso Nacional (CN) e a manifestação da Procuradoria Geral da República (PGR)

No parecer (21) observa-se argumentos contrapostos entre a CNTU e os órgãos informantes: AGU, CN e PR. Esses órgãos foram chamados pela Ministra Rosa Weber relatora - à prestar informações no processo judicial, com base no rito do art. 12 da Lei $9.868 / 1999$ (30).

Observa-se que dentre os fundamentos apresentados na ADI e aqueles encontrados nos artigos selecionados, quer na BVS, quer na literatura complementar não houve coincidências. As informações prestadas pelas partes não apresentaram fundamentos segundo o emanado pelos autores estudados, exceto por Chioro (23), uma vez que os informantes no processo concordam com à constitucionalidade da lei.

Até a data de encerramento dessa pesquisa, novembro de 2015, a Ação Direta de Inconstitucionalidade 5239/15 ainda não havia sido julgada pelo Supremo Tribunal Federal. (21). 
Resta mencionar, e somente para fins de informação, que está em trâmite na Câmara dos Deputados, um projeto de lei, proposto pela deputada federal Jandira Feghali, de $n^{\circ}$. 1721/2015, (31) que propõe alterar a lei 8.080/90 modificada pelo art. 142 da lei 13.097/2015 e, portanto, corrigir o que a mesma enxerga como erro.

Segundo a deputada:

O domínio pelo capital estrangeiro na saúde brasileira inviabiliza o projeto do SUS e, consequentemente, o direito à saúde, tornando a saúde um bem comerciável, ao qual somente quem tem dinheiro tem acesso.

O projeto de lei $\mathrm{n}^{\circ}$. 1721/2015 elenca como potenciais fatores negativos da alteração da lei 8.080/1990 pela lei 13.097/2015: "a quebra da universalidade e a consolidação da mercantilização da saúde"; o reforço da "dupla porta" no acesso a saúde onde quem pode pagar tem acesso "facilitado e mais ágil e os demais estão fadados aos serviços de menor agilidade"; aumento na "drenagem dos profissionais de saúde do setor público para o privado", a "redução da qualidade de atenção diante da falta de controle do setor público em função de estratégias externas que maximizam o lucro" e ainda as "dificuldades de desenvolvimento do setor privado caso conglomerados internacionais adquiram numerosos serviços de saúde e passem a estabelecer os padrões de atenção, e, até de preços praticados".

\section{Considerações finais}

O presente artigo teve seus objetivos atingidos na medida em que apresentou elementos que circundam o debate sobre a entrada do capital estrangeiro na saúde, conforme artigo 142, da lei n.13.097/15.

Nota-se, contudo, que não é possível observar relações entre os artigos apresentados, em momento prévio à sanção da lei mencionada, e o PLS 259/2009, que tratava do assunto.

Da mesma forma, observada a MP 656/2014, essa não contou em seus fundamentos, com estudos já existentes e nem apresentou exposição de motivos compatível com os benefícios elencados pelos defensores da entrada do capital estrangeiro no setor saúde brasileiro. A inserção da produção legislativa só pode ser observada nos artigos estudados, em momento posterior à sanção da lei n.13.097/15. 
Essa afirmativa pode denotar falhas nas relações entre o poder legislativo, o sistema de saúde e a própria sociedade civil organizada, na medida em que não opinam e nem reconhecem a atuação uns dos outros.

Há que se crer que o tema não é de reflexão simples, uma vez que traz repercussões sociais de grande significado à sociedade brasileira, em especial, à saúde pública.

No cenário pós-lei n. 13.097/15, o Hospital Samaritano, instituição filantrópica, localizada na cidade de São Paulo, foi vendida para a multinacional United Health, mesma companhia compradora da Amil, em 2012. A situação da compra tende a modificar o perfil da instituição visto que a mesma passa a visar lucro, cenário não condizente com os princípios básicos da filantropia e atendimento ao usuário do Sistema Único de Saúde.

Em suma, a entrada do capital estrangeiro no setor poderá denotar modificações para a saúde complementar, na medida em que hospitais filantrópicos são opções únicas de acesso à saúde aos usuários do SUS em determinadas localidades do Brasil. Caso ocorra a internacionalização das instituições filantrópicas, essas deixam de prestar serviço complementar ao SUS, desassistindo os usuários locais e obrigando-lhes acesso mediante saúde suplementar ou desembolso direto.

Contudo, conforme todo o exposto, cabe ao STF, órgão competente para a análise e julgamento da ADI 5239/2015 que refere à lei n. 13.019/2015, indicar a interpretação adequada aos ditames constitucionais. Nesse contexto, é possível que o STF perpasse por questões que refiram o contrabando legislativo, a assistência à saúde e outros pontos apresentados no decorrer do artigo.

\section{Referências}

1- Brasil. Constituição da República Federativa do Brasil, 8 de outubro de 1988. Brasilia: Senado Federal; 1988.

2. Lei no. 8.080/90, de 19 de setembro de 1990. Lei Orgânica da Saúde.

Dispõe sobre as condições para a promoção, proteção e recuperação da saúde, a organização e o funcionamento dos serviços correspondentes e dá outras providências. Brasília. Diário Oficial da União 20 set 1990; Disponível em http://www.planalto.gov.br/ccivil 03/Leis/L8080.htm. [Acesso 20 set. 2015]. 
3- $\quad$ Paim. JS, Silva. LMV. Universalidade, integralidade, equidade e SUS. Bis, Bol. Inst. Saúde. v. 12 (2). São Paulo. Ago. 2010. [Acesso em 29 ago 2015]. Disponível em: http://periodicos.ses.sp.bvs.br/scielo.php?script=sci arttext\&pid=s1518$18122010000200002 \& \operatorname{lng}=\mathrm{pt} \& \mathrm{nrm}=\mathrm{iso}$

4- Brasil. Lei №.13.097, art 142. de 19 de janeiro de 2015. Reduz a zero as alíquotas da Contribuição para o PIS/PASEP, da COFINS, da Contribuição para o PIS/PasepImportação e da Cofins-Importação incidentes sobre a receita de vendas e na importação de partes utilizadas em aerogeradores; prorroga os benefícios previstos nas Leis nos 9.250, de 26 de dezembro de 1995, 9.440, de 14 de março de 1997, 10.931, de 2 de agosto de 2004, 11.196, de 21 de novembro de 2005, 12.024, de 27 de agosto de 2009, e 12.375, de 30 de dezembro de 2010; altera o art. 46 da Lei no 12.715, de 17 de setembro de 2012, que dispõe sobre a devolução ao exterior ou a destruição de mercadoria estrangeira cuja importação não seja autorizada; altera as Leis nos 9.430, de 27 de dezembro de 1996, 12.546, de 14 de dezembro de 2011,12.973, de 13 de maio de 2014, 9.826, de 23 de agosto de 1999, 10.833, de 29 de dezembro de 2003, 10.865, de 30 de abril de 2004, 11.051, de 29 de dezembro de 2004, 11.774, de 17 de setembro de 2008, 10.637, de 30 de dezembro de 2002, 12.249, de 11 de junho de 2010, 10.522, de 19 de julho de 2002, 12.865, de 9 de outubro de 2013,10.820, de 17 de dezembro de 2003, 6.634, de 2 de maio de 1979, 7.433, de 18 de dezembro de 1985, 11.977, de 7 de julho de 2009, 10.931, de 2 de agosto de 2004, 11.076, de 30 de dezembro de 2004, 9.514, de 20 de novembro de 1997, 9.427, de 26 de dezembro de 1996, 9.074, de 7 de julho de 1995, 12.783, de 11 de janeiro de 2013, 11.943, de 28 de maio de 2009, 10.848, de 15 de março de 2004, 7.565, de 19 de dezembro de 1986, 12.462, de 4 de agosto de 2011, 9.503, de 23 de setembro de 1997, 11.442, de 5 de janeiro de 2007, 8.666, de 21 de junho de 1993, 9.782, de 26 de janeiro de 1999, 6.360, de 23 de setembro de 1976, 5.991, de 17 de dezembro de 1973, 12.850, de 2 de agosto de 2013, 5.070, de 7 de julho de 1966, 9.472, de 16 de julho de 1997, 10.480, de 2 de julho de 2002, 8.112, de 11 de dezembro de 1990,6.530, de 12 de maio de 1978, 5.764, de 16 de dezembro de 1971, 8.080, de 19 de setembro de 1990,11.079, de 30 de dezembro de 2004, 13.043, de 13 de novembro de 2014, 8.987, de 13 de fevereiro de $1995,10.925$, de 23 de julho de 2004, 12.096, de 24 de novembro de 2009, 11.482, de 31 de maio de 2007, 7.713, de 22 de dezembro de 1988. 19 de janeiro 2015. [Acesso em 23 jul. 2015]. Disponível em: http://www.planalto.gov.br/ccivil 03/ ato20152018/2015/lei/L13097.htm

5- Guimaraes. MS. Investimento estrangeiro e desenvolvimento econômico: breve análise dos efeitos benéficos e nocivos do capital estrangeiro. Revista do Mestrado em Direito. Universidade Católica de Brasília. [Acesso em 29 ago 2015.] Disponível em: http://www.scielo.br/scielo.php?script=sci arttext\&pid=S0103-40142000000200011

6- Brasil. Lei no. 9.656, DE 3 de Junho de 1998. Dispõe sobre os planos e seguros privados de assistência à saúde. Brasília. [Acesso em 2 nov. 2015]. Diário Oficial da União. 4 julho de 1998.Disponivel

em:http://www.planalto.gov.br/ccivil_03/Leis/L9656.htm 
7- $\quad$ Levi ML, Mendes A. Gasto Total com Saúde no Brasil: a importância e o esforço de medi-lo. Associação Brasileira da Saúde Coletiva. 24 maio 2015. [Acesso em 22 de set. 2015]. Disponível em: http://www.abrasco.org.br/site/wp -

content/uploads/2015/06/Domingueira-da-Sa\%C3\%BAde-008-2015-24-05-2015.pdf

8- $\quad$ Sarlet. IW, Figueiredo. MF. Algumas considerações sobre o direito fundamental à proteção e promoção da saúde aos 20 anos da Constituição Federal de 1988. [Acesso em 2 nov 2015]. Disponível em:

http://www.stf.jus.br/arquivo/cms/processoAudienciaPublicaSaude/anexo/O_direito_a_sa ude_nos_20_anos_da_CF_coletanea_TAnia_10_04_09.pdf

9- $\quad$ Mattos. PC. Tipos de Revisão de Literatura. 2015. Faculdade de Ciências Agronômicas. [s.n.].[Acesso em 2 nov. 2015]. Disponível em: http://www.fca.unesp.br/Home/Biblioteca/tipos-de-evisao-de-literatura.pdf

10- Minayo. MCS. O desafio do conhecimento. Pesquisa Qualitativa 10 ed. São Paulo. Hucitec, Abrasco 2007.

11- Scheffer.M. O capital estrangeiro e a privatização do sistema de saúde brasileiro. Cadernos de Saúde Pública, 1 (34) abril de 2015. [Acesso em 20 set 2015]. Disponível em http://www.scielo.br/scielo.php?pid=S0102-

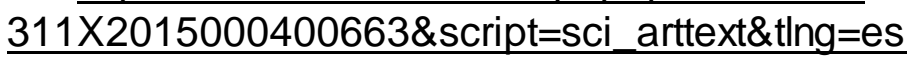

12- Sacramento. I. Revigorar a saúde pública em tempos de crise. Revista Eletrônica de Comunicação, Informação \& Inovação em Saúde. 9 (3):1-2, 2015. [Acesso em 20 set. 2015]. Disponível em:

http://www.reciis.icict.fiocruz.br/index.php/reciis/article/view/1038/1976

13- Barros. FPC, Filho, AN. Cobertura universal de saúde. Cad. Saúde Pública 31 (6):1. 2015. [Acesso em 20 set.2015]. Disponível em:

http://www.scielosp.org/pdf/csp/v31 n6/0102-311X-csp-31-6-1333.pdf

14- Monken. SF, Motta. LJ, Schwach CG, Oliveira. GM. Abordagem bibliométrica sobre a governança corporativa no setor da saúde. Perspectivas em Gestão \& Conhecimento 5, Número Especial, p. 57-68, out. 2015. [Acesso em 20 set 2015]. Disponível em http://www.ies.ufpb.br/ojs/index.php/pgc/article/view/26179/14111

15- Mendes. A, Louvison. M. O debate da regionalização em tempos de turbulência no SUS. Saúde e Sociedade 24 (2): 393-402, 2015. [Acesso em 20 set. 2015].

Disponível em http://www.scielo.br/scielo.php?pid=S0104$12902015000200393 \&$ script=sci arttext

16- Costa. MDH, Vasconcelos. KELA, Oliveira. LC. Tríade da saúde como política da seguridade: (Des) Considerações sobre intersetorialidade, promoção da saúde e participação no cotidiano do SUS. 2015. [Acesso em 20 set 2015]. Disponível em http://www.joinpp.ufma.br/jornadas/joinpp2015/pdfs/mesas/a-triade-da-saude-comopolitica-da-seguridade .pdf 
17- Prefeitura Municipal de São Paulo. Conselho Municipal de Saúde - São Paulo. Ata de reunião. [Acesso em 20 set 2015]. Disponível em http://www.prefeitura.sp.gov.br/cidade/secretarias/upload/saude/Atada195ReuniaoOrdin ariadoCMS14e2105.pdf

18- Brasil. Projeto de Lei do Senado Federal. 2009. Senador Flecha Ribeiro. Acesso em 29 agosto 2015. [Acesso em 2 set. 2015]. Disponível em http://www25.senado.leg.br/web/atividade/materias/-/materia/91666.

$19-$ Senado Federal. Medida Provisória 656/2014. Medida provisória ํㅜ 656 de 2014. Reduz a zero as alíquotas da Contribuição para o PIS/PASEP, da COFINS, da Contribuição para o PIS/Pasep-Importação e da Cofins-Importação incidentes sobre a receita de vendas e na importação de partes utilizadas em aerogeradores, prorroga benefícios, altera o art. 46 da Lei no 12.715, de 17 de setembro de 2012, que dispõe sobre a devolução ao exterior ou a destruição de mercadoria estrangeira cuja importação não seja autorizada, e dá outras providências. [Acesso em 2 2015]. Disponível em: Disponível em:http://presrepublica.jusbrasil.com.br/legislacao/144192070/medida-provisoria-656-14

20Disponível em Ação de Inconstitucionalidade 5.239/15. [Acesso em 2 nov. 2015.] http://www.stf.jus.br/portal/processo/verProcessoAndamento.asp? numero $=5239$ \& classe $=\mathrm{AD}$ \& $\&$ origem $=\mathrm{AP} \&$ recurso $=0$ \& tipoJulgamento $=\mathrm{M}$

21- Manifestação da Procuradoria Geral da República. [Acesso em 2 nov. 2015]. Disponível em http://www.stf.jus.br/portal/processo/verProcessoAndamento.asp?incidente=4710404

22- Santos. MS. Investimento estrangeiro e desenvolvimento econômico: breve análise dos efeitos benéficos e nocivos do capital estrangeiro.2000. Estudos Avançados. 2015. [Acesso em 2 de nov. 2015.] Volume 14 n 39. Disponível em http://www.scielo.br/scielo.php?script=sci_arttext\&pid=S0103$40142000000200011 \&$ lng=en\&tlng=pt.

23- Formenti. L. Ministro da Saúde defende capital no setor saúde. O Estadão de 27 jan 2015. [Acesso em 22 de set.2015]. Disponível em http://saude.estadao.com.br/noticias/geral,ministro-da-saude-defende-abertura-decapital-na-saude, 1625684

24- Santos. MA, Bellagamba, LP. Borges KFB. O papel da Advocacia Geral da União na judicialização das políticas de saúde. Revista Cadernos lbero-Americanos 2 (2), 2013. [Acesso em 29 set. 2015]. Disponível em http://www.cadernos.prodisa.fiocruz.br/index.php/cadernos/article/view/94 
25- Associação Brasileira de Saúde Coletiva. Capital Estrangeiro na saúde é tema de entrevista com o presidente da Abrasco - ABRASCO. [Acesso em 2 nov. 2015]. Disponível em: http://www.abrasco.org.br/site/2015/03/9652/

26- Brasil. Lei $n^{\circ} 4.131 / 62$. Disciplina a aplicação do capital estrangeiro e as remessas de valores para o exterior e dá outras providências. Diário Oficial da União. 3 set de 1962. [Acesso em 22 de set. 2015]. Disponível em: http://www.planalto.gov.br/ccivil 03/LEIS/L4131.htm

27. Lei Complementar n 95/1988. [Acesso em 2 nov. 2015]. Dispõe sobre a elaboração, a redação, a alteração e a consolidação das leis, conforme determina o parágrafo único do art. 59 da Constituição Federal, e estabelece normas para a consolidação dos atos normativos. Disponível em: http://www.planalto.gov.br/ccivil 03/leis/lcp/lcp95.htm

28- Agencia Brasil. STF proíbe contrabando legislativo na tramitação de Medidas Provisórias. [Acesso em 2 nov. 2015.] Disponível em: http://www.ebc.com.br/noticias/politica/2015/10/stf-proibe-contrabando-legislativo-natramitacao-de-medidas-provisorias

29- Glossário jurídico STF. [Acesso em 14 nov 2015]. Disponível em http://www.stf.jus.br/portal/glossario/verVerbete.asp?letra=A\&id=124

30- Brasil. Lei 9.868/99, de 10 de novembro de 1999. Dispõe sobre o processo e julgamento da ação direta de inconstitucionalidade e da ação declaratória de constitucionalidade perante o Supremo Tribunal Federal. [Acesso em 2 nov 2015]. Disponível em: http://www.planalto.gov.br/ccivil_03/leis/L9868.htm

$31-$ . Projeto de Lei da Câmara dos Deputados 1721. 2015. Jandira Feghali. [Acesso em 6 nov. 2015.] Disponível em http://www.camara.gov.br/proposicoesWeb/fichadetramitacao?idProposicao=1299732

Recebido em 3/1/2016 Aprovado em 19/5/2016

Como citar este artigo:

Brito EM, Santos AO. A abertura do capital estrangeiro ao setor saúde: os debates que envolvem o tema. Revista Cadernos Ibero-Americanos de Direito Sanitário. 2016 abr./jun, 5(2):74-91. 